\title{
Caracterização litográfica de reservatório, Vera Cruz - BA
}

Kesia de Souza Braun* (UFVJM); Carlos Henrique Alexandrino (UFVJM)

Copyright 2016, SBGf - Sociedade Brasileira de Geofísica

Este texto foi preparado para a apresentação no VII Simpósio Brasileiro de Geofísica, Ouro Preto, 25 a 27 de outubro de 2016. Seu conteúdo foi revisado pelo Comitê Técnico do VII SimBGf, mas não necessariamente representa a opinião da SBGf ou de seus associados. É proibida a reprodução total ou parcial deste material para propósitos comerciais sem prévia autorização da SBGf.

\section{Resumo}

A perfilagem geofísica auxilia no conhecimento das propriedades de um reservatório, fornecendo grande quantidade de informação. Entretanto, os dados devem ser analisados em conjunto e corretamente, evitando interpretações falsas no resultado final. Desta forma, este trabalho consiste na caracterização em conjunto dos perfis do reservatório 3M $0007 \mathrm{BA}$, localizado no campo de Morro do Barro, Vera Cruz - BA. Foram utilizados perfis elétricos, além de amostras de calha. Após a interpretação, foi possível identificar principalmente trechos com a presença de gás, caracterizando o reservatório como um poço voltado à extração de gás. Através dos resultados finais é possível mapear poços com gráficos ou figuras que nos mostram as áreas de interesse a serem trabalhadas.

\section{Introdução}

Chamamos perfilagem ao levantamento completo de perfis referentes ao poço para a produção de petróleo. O perfil de um poço é a imagem visual, em relação à profundidade, de uma ou mais características ou propriedades das rochas perfuradas. Ele é obtido a partir de ferramentas que são descidas no poço, onde os valores são captados e em seguida são armazenados em arquivos digitais.

Apesar de existirem vários processos físicos de medição (perfis), os dados fornecidos pelos equipamentos eletrônicos de medida são chamados genericamente de perfis elétricos. Através da perfilagem é possível mapear poços com gráficos ou figuras que nos mostram as áreas de interesse a serem trabalhadas, no entanto, é bom deixar claro que ela não se mostra auto-suficiente, pois necessita de técnicas auxiliares que se complementam para cumprir essa meta. Como exemplo de uma técnica auxiliar temos a amostra de calha que é utilizada juntamente com os perfis elétricos para ajudar na identificação das litofaces. Essa amostra contém os resíduos das formações rochosas, durante a perfuração, que permanecem na broca quando ela é levantada do interior do poço para a superfície.

Os perfis geofísicos segundo SILVA (2009) têm como principal objetivo auxiliar em um melhor conhecimento das características do reservatório, tais como: porosidade, litologia, argilosidade, permeabilidade e densidade. De posse das características do reservatório é possível predizer a qualidade do reservatório, o que traz maior segurança quanto à determinação dos locais de perfuração, economizando tempo e prolongando a vida útil do campo, no que se refere à produção de cada poço (SACCO, 2007).

O objetivo principal deste trabalho é caracterizar o poço 3M 0007 BA, localizado no campo de Morro do Barro, descoberto em 22 de abril de 1962, na porção sudoeste da ilha de Itaparica, no município de Vera Cruz, através da análise das técnicas de perfilagem geofísica.

Esse campo entrou em produção em 30 de setembro de 1964 e produziu, até 1988 , uma acumulada de 86 mil m$^{3}$ de gás de arenitos da Formação Salvador. A produção do óleo, de $42^{\circ} \mathrm{API}$, foi irrelevante. Não houve injeção de água nem de qualquer outro fluido no campo. A área do antigo campo, devolvido à ANP, é de $4,7 \mathrm{~km}^{2}$, onde foram realizados $20 \mathrm{~km}$ de linhas sísmicas $2 \mathrm{D}$ e perfurados 11 poços. O poço 3-MB-7-BA com latitude $13332.62 \mathrm{~S}$ e longitude $384459.42 \mathrm{~W}$, que será objeto de nosso estudo teve o início de sua perfuração em 17 de novembro de 1969 e término em 29 de janeiro de 1970.

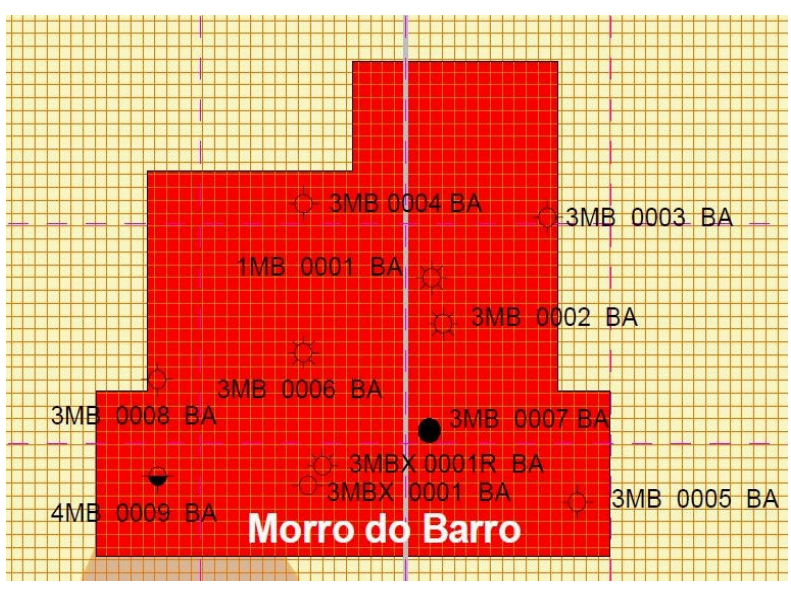

Figura 1 - Campo de Morro do Barro e Poço "3MB 0007 BA" (modificado de ANP mapas \& Sacco, T.).

\section{Metodologia}

Podemos citar alguns dos principais tipos de perfis elétricos utilizados:

Raios Gama (GR) - Medida baseada na emissão radioativa natural de rochas que contém potássio 40 ou elementos da série urânio-tório. Ideal para o cálculo do volume de argila e volume de rocha do reservatório. $\mathrm{O}$ índice de raios gama é dado em API por:

$$
I G R=\frac{G R_{\text {lido }}-G R_{\text {minimo }}}{G R_{\text {máximo }}-G R_{\text {minimo }}}
$$

O volume de argila é dado por:

$$
V_{s h}=0,33\left(2^{2^{*} I G R}-1\right)
$$

Neutrônico (NPHI) - Utilizado para estimativa de porosidade, litologia e detecção de hidrocarbonetos leves ou gás. 
Resistividade (ILD) - Habilidade da formação geológica em resistir à passagem de um fluxo de corrente elétrica, permitindo identificar o tipo de fluido que preenche os interstícios do reservatório. A resposta do perfil de Resistividade para a água salgada, doce e óleo é mostrada na Figura 1:

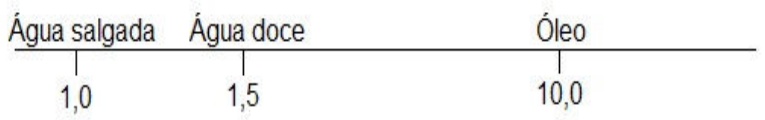

Figura 2 - Faixa de resistividade (em $\Omega$.m) da água salgada, água doce e óleo.

Sônico (DT) - Relaciona diretamente o tempo de trânsito e a porosidade da formação rochosa. O tempo de transito é dado em $\mu \mathrm{s} / \mathrm{ft}$ e a porosidade sônica é calculada em (\%) pela fórmula 3 :

$$
\phi t=\frac{\Delta t_{\text {lido }}-\Delta t_{\text {matriz }}}{\Delta t_{\text {fluido }}-\Delta t_{\text {matriz }}}
$$

Densidade (RHOB) - Caracteriza a densidade média de uma unidade litológica da formação (rocha e fluido). A densidade é obtida em $\mathrm{g} / \mathrm{cm}^{3}$ e é possível calcular a porosidade-densidade, em (\%), por:

$$
\phi \rho=\frac{\rho_{\text {matriz }}-\rho_{\text {lido }}}{\rho_{\text {matriz }}-\rho_{\text {fluido }}}
$$

Para este cálculo utilizou-se a densidade da matriz quartzosa como sendo $2,65 \mathrm{~g} / \mathrm{cm}^{3}$ e a do fluido da água, $1,00 \mathrm{~g} / \mathrm{cm}^{3}$.

Caliper (CALI) - Fornece o diâmetro do poço. É aplicado no cálculo do volume de cimento para tampões ou cimentação do revestimento, apoio a operações de teste de formação, controle de qualidade de perfis e indicações das condições do poço em um determinado intervalo.

Potencial Espontâneo (SP) - Registro da diferença de potencial entre um eletrodo móvel descido dentro do poço e outro fixo na superfície. Este perfil permite determinar as camadas permoporosas, calcular a argilosidade das rochas, a resistividade da água da formação e auxiliar na correlação de informações com poços vizinhos.

Para um melhor aproveitamento dos perfis elétricos obtidos, é necessário que eles sejam utilizados em conjunto, facilitando a interpretação dos mesmos. Outra ferramenta bastante utilizada para caracterização de reservatórios é a testemunhagem, onde durante a perfuração do reservatório, várias amostras das rochas são coletadas, aumentando o conhecimento do subsolo. Em laboratórios, testes são efetuados para obter informações a respeito da litologia, textura, porosidade, permeabilidade, saturação de óleo e água.

O intervalo entre 0 e 100 metros foi desconsiderado por apresentar muitas falhas de dados, sendo assim a área escolhida para interpretação dos perfis foi o intervalo entre 100 e 2000 metros, sendo obtidos os seguintes dados apresentados nas figuras $3,4,5$ e 6 :

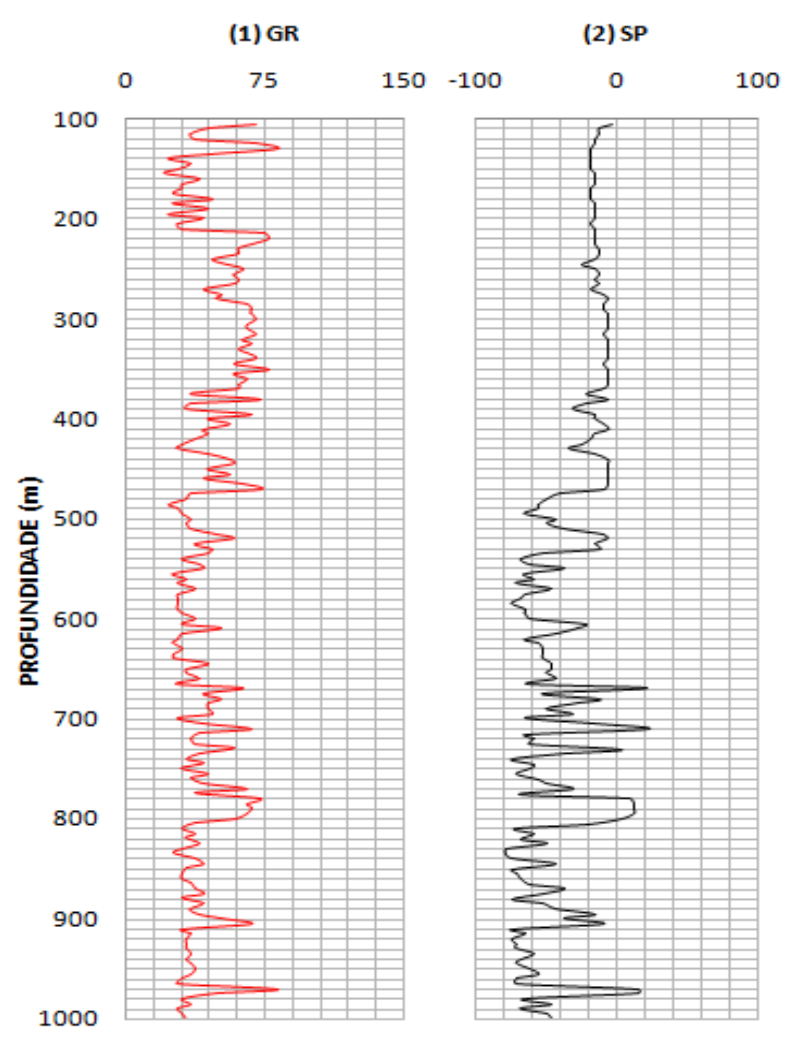

Figura 3 - Gráfico das variáveis (1) GR, (2) SP; versus profundidade do poço, no intervalo de 100 a 1000 metros.

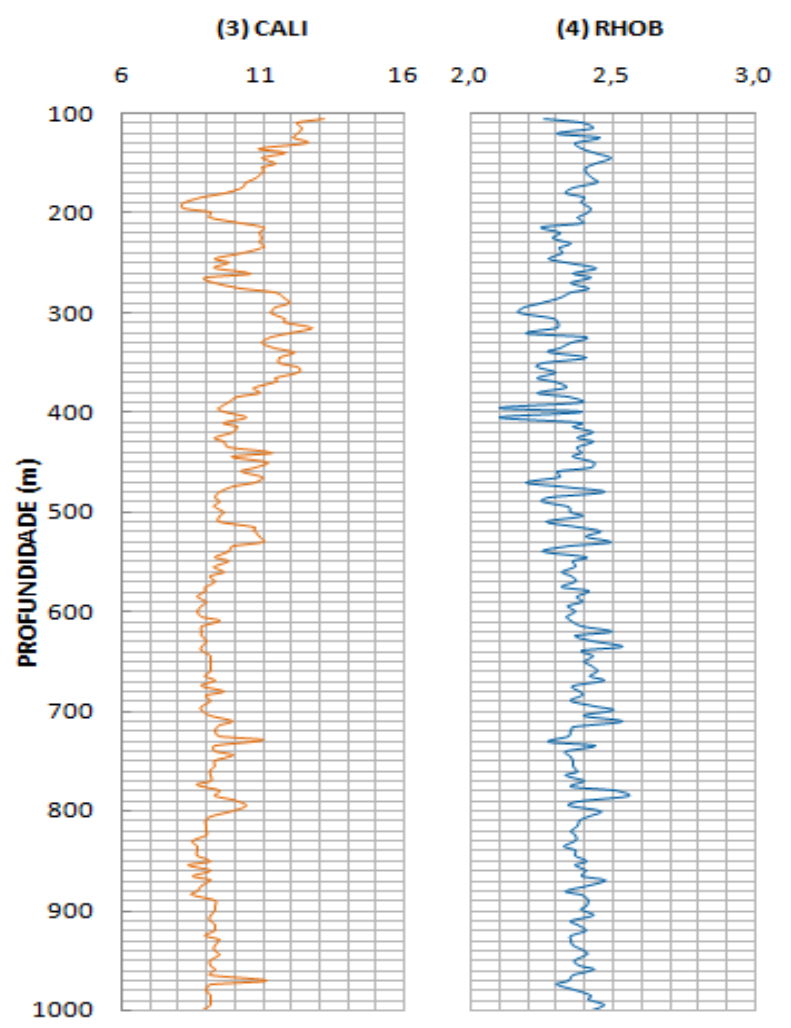

Figura 4 - Gráfico das variáveis (3) CALI, (4) RHOB; versus profundidade do poço, no intervalo de 100 a 1000 metros. 


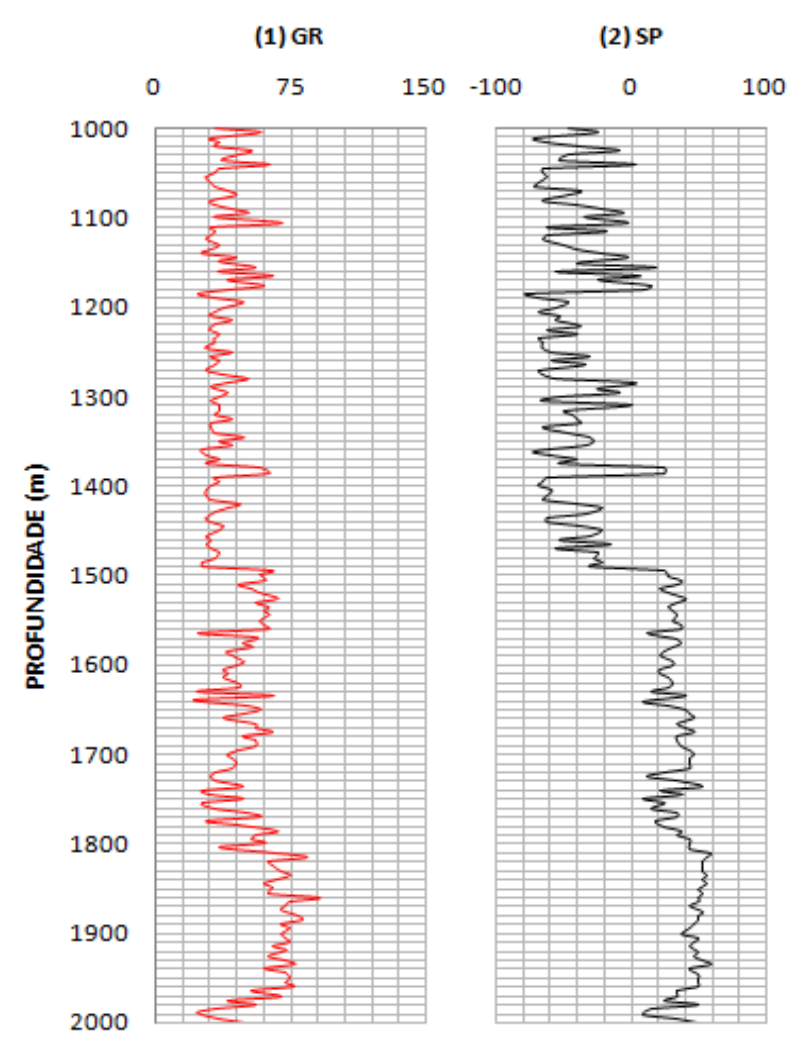

Figura 5 - Gráfico das variáveis (1) GR, (2) SP; versus profundidade do poço, no intervalo de 1000 a 2000 metros.
(3) CALI

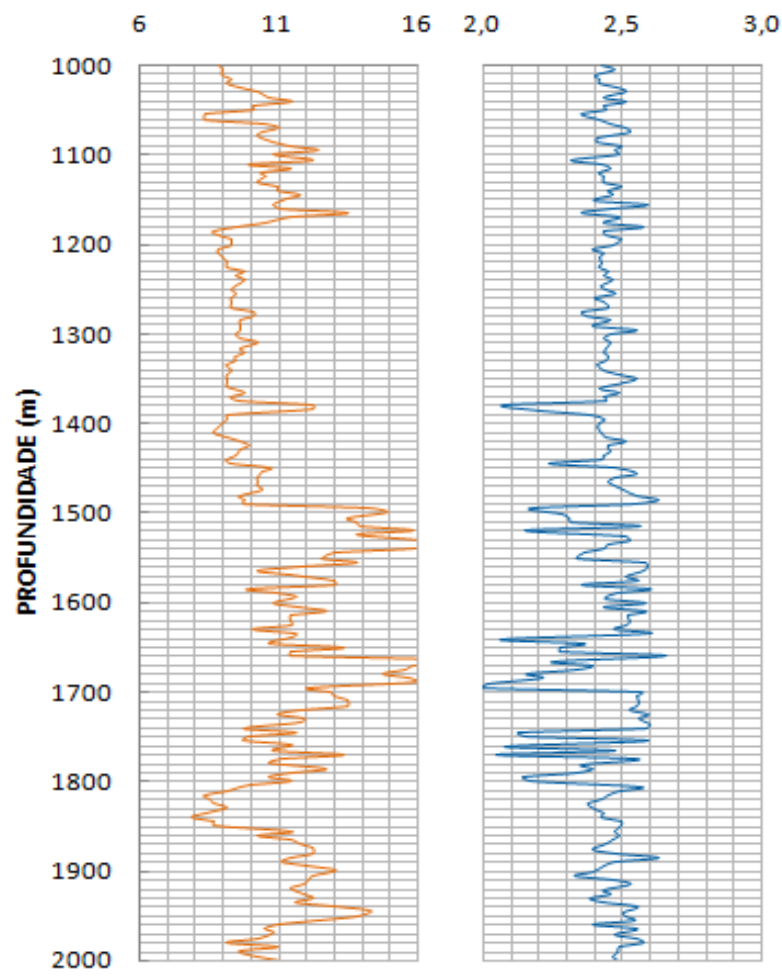

Figura 6 - Gráfico das variáveis (3) CALI, (4) RHOB; versus profundidade do poço, no intervalo de 1000 a 2000 metros.

\section{Resultados}

Para melhor compreensão e estudo do reservatório, realizou-se o cálculo das propriedades estatísticas, entre elas: média, mediana, percentual da variância, desvio padrão e desvio médio para cada método geoelétrico aplicado no estudo. Dados que são apresentados a seguir, na tabela 1.

Tabela 1 - Resumo das estatísticas descritivas do poço.

\begin{tabular}{|c|c|c|c|c|c|}
\hline Variáveis & Média & Mediana & Variância & $\begin{array}{c}\text { CV } \\
\mathbf{( \% )}\end{array}$ & $\begin{array}{c}\text { Desvio } \\
\text { Padrão }\end{array}$ \\
\hline PROF & & 1050,00 & & & \\
\hline GR & 45,22 & 39,84 & 245,71 & 2,46 & 15,68 \\
\hline SP & $-16,32$ & $-15,63$ & 1617,33 & 16,17 & 40,22 \\
\hline CALI & 10,43 & 9,91 & 2,70 & 0,03 & 1,64 \\
\hline RHOB & 2,40 & 2,42 & 0,01 & 0,00 & 0,10 \\
\hline
\end{tabular}

Para a caracterização do poço 3-MB-7-BA utilizou-se os métodos geoelétricos descritos anteriormente. A área de interesse foi fixada na faixa de profundidade de 100 a 2000 metros, onde foram observadas as ocorrências dos perfis Raio Gama (GR), Densidade (RHOB), Caliper (CALI), Potencial Espontâneo (SP), Indução (ILD) e testemunhos.

Calculou-se o índice de argilosidade (IGR) pela equação 1 , fixando o GR mínimo em 21 API e o máximo em 91 API. O GR médio lido foi 45 API e utilizando a equação 2 foi possível o cálculo do índice de argilosidade médio $\left(\mathrm{V}_{\mathrm{SH}}\right)$, que resultou em $20,1 \%$ de argilosidade. Como grande parte dos valores de $\mathrm{V}_{\mathrm{SH}}$ descritos nas figuras $7 \mathrm{e}$ 8 são inferiores a $50 \%$, inclusive o valor médio, essas posições devem ser usadas para a instalação de filtros. $O$ poço em estudo pode ser considerado um reservatório com alguma concentração de argila, sendo favorável para que haja uma maior ligação entre seus grãos, evitando desmoronamentos.

A curva do Potencial Espontâneo (SP) mostra uma tendência quase retilínea na faixa entre 100 e 370 metros, o que caracteriza a presença de folhelhos, sendo confirmada pela análise dos testemunhos. Entre 370 e 1500 metros, a curva do SP apresenta deflexões para a esquerda (negativa), o que caracteriza camadas permeáveis e água intersticial mais salgada que o filtrado. Em trechos, como entre 780 e 800 metros e 1500 a 2000 metros, é possível observar camadas permeáveis com deflexões para a direita (positiva) caracterizando o filtrado como mais salgado que a água intersticial.

Analisando o perfil do Caliper para a verificação das condições do poço, em conjunto com a identificação das camadas de folhelho pelo perfil de Raios Gama. Observa-se, que as paredes do poço não se encontram em boas condições de preservação, pois a variação (em polegadas) ao longo de quase todo o perfil mostrou-se considerável, uma vez que o acumulo de filtrado na parede do poço é ocorrente em camadas porosas como arenitos e os arrombamentos são característicos de camadas inconsolidadas, ocorrendo tipicamente em folhelhos. Os trechos entre 100 e 105 metros e entre 1500 e 1800 metros são exemplos claros, onde podemos observar variações abruptas do diâmetro do poço, em 
que se encontram camadas de folhelho comprovadas pela análise do perfil Raio Gama.

Pelo perfil da Resistividade (ILD) podemos delimitar os trechos entre 150 a 200 metros, 370 a 400 metros, 475 a 505 metros e 1625 a 1650 como zonas possíveis de gás. Impressões que se confirmaram pelos testes de formação realizados. Valores de resistividade de ordem menor que dois são verificados nos trechos entre 210 e 240 metros e 1970 a 2000 metros, possíveis de apresentar água.

Zonas de hidrocarbonetos são identificadas nos trechos entre 390 a 410 metros, 1385 a 1400 metros, 1615 a 1700 metros e 1720 a 1805 metros, confirmadas pelas curvas do RHOB e $\varnothing$ sh (porosidade total lida no folhelho). Do perfil de resistividade os intervalos de 370 a 400 metros, 475 a 505 metros, 1625 a 1650 metros, 210 a 240 metros e 1970 a 2000 metros apresentam zonas possíveis de gás e água salgada.

Pelas amostras de calha podemos observar que praticamente toda a extensão do poço em estudo é formado por Arenito caracterizado como uma rocha sedimentária de origem detrítica formada de grãos agregados por um cimento natural silicoso, e Folhelhos caracterizado como rocha sedimentar, de granulação fina, com tendência a dividir-se em folhas segundo a estratificação. Havendo algumas exceções em trechos com a presença de Calcáreo e Siltito. Esses materiais comprovam a curva do perfil Caliper, em que existem desmoronamentos em toda a extensão do poço, justificados pelas características do Arenito e Folhelho.

Através das equações (1), (2) e (4) foi possível obter as curvas do Índice de Raios Gama (IGR), o Volume de Argila (Vsh) e a Porosidade total lida no folhelho ( $\varnothing$ sh), apresentados a seguir nas figuras 7 e 8 .

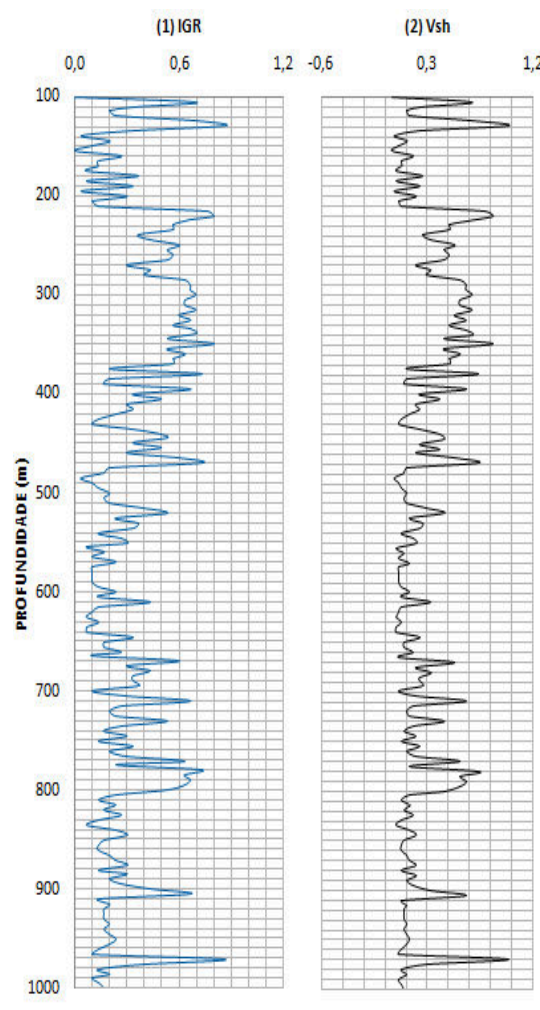

Figura 7 - Gráfico das variáveis (1) IGR, (2) Vsh, (3) øsh; versus profundidade do poço, no intervalo de 100 a 1000 metros.

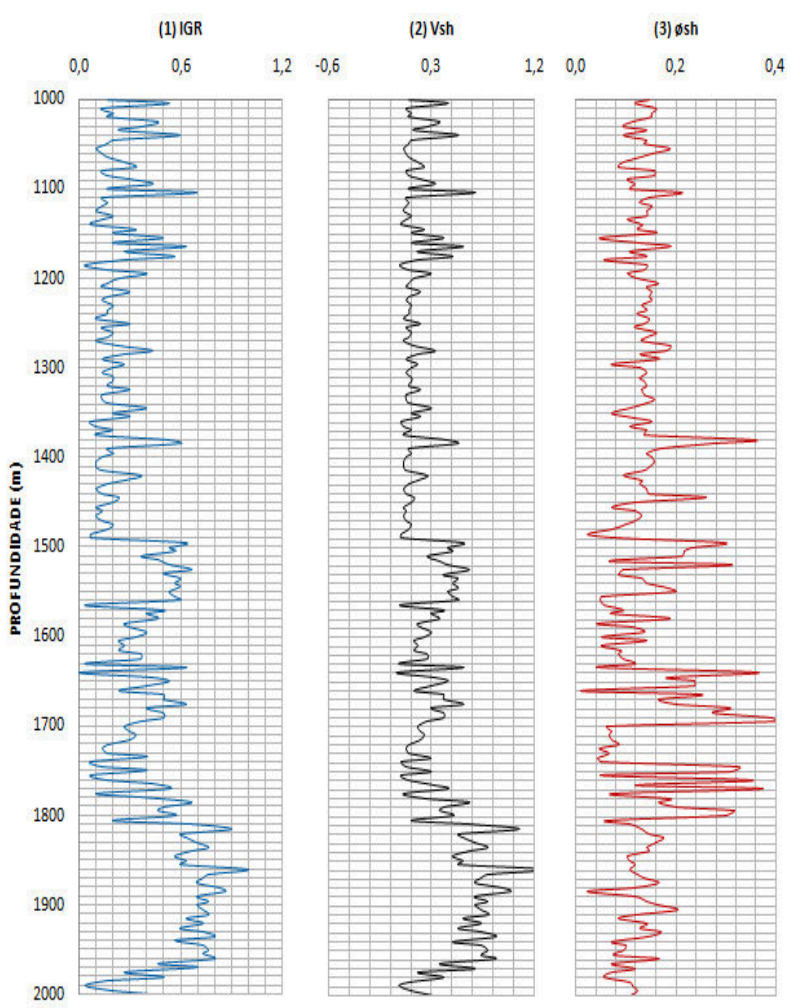

Figura 8 - Gráfico das variáveis (1) IGR, (2) Vsh, (3) øsh; versus profundidade do poço, no intervalo de 1000 a 2000 metros.

\section{Discussão e Conclusões}

Os perfis de poços são usados principalmente na prospecção de petróleo e água subterrânea. Para realizar a perfilagem em um poço, são usados desde diversos sensores acoplados a sofisticados aparelhos eletrônicos. Estes sensores são introduzidos dentro do poço, registrando, a cada profundidade, as diversas informações relativas às características físicas das rochas e dos fluidos. Estes dados, após coletados passam por diversos processos de análise possibilitando a geólogos e geofísicos um melhor conhecimento das propriedades de um reservatório e diminuindo as incertezas em relação às suas características, gerando grande quantidade de informações.

Através das técnicas de interpretação de perfis de poços, aplicada aos dados relativos ao poço $3 \mathrm{M} 0007 \mathrm{BA}$, no intervalo entre 100 a 2000 metros, o presente trabalho ajudou a confirmar a informação de que o poço foi perfurado em um campo contendo óleo, porém no poço e intervalo analisados observou-se predominância de gás e água salgada, confirmada pelas amostras de rocha extraídas e pelos testes de formação realizados, sendo encontrado gás na Formação Salvador em várias áreas, assim o poço fica caracterizado como um reservatório produtor de gás.

\section{Referências}


Carvalho, P. B. 2014. Caracterização Petrofísica do Campo de Namorado a Partir de Perfis de Poço. Trabalho de Conclusão de Curso, Departamento de Geologia e Geofísica, Universidade Federal Fluminense, Niterói.

Drummond, A. A. R. Química de Fluidos de Perfuração para Poços de Petróleo - Perfilagem. Instituto de Química, Universidade Federal do Rio de Janeiro, Rio de Janeiro.

Pinheiro, L. N. P. 2014. Caracterização do reservatório Carapebus do campo de Peregrino, bacia de Campos, através da análise de perfis geofísicos de poços, integrada à interpretação sísmica. Trabalho de Conclusão de Curso, Universidade Federal Fluminense, Niterói.

Russo, S. L; Camargo, M. E; Simon, V. H. 2010. Avaliação de Perfis Sônicos Sintéticos em Poços de Petróleo Perfurados nas Unidades Geológicas Pertencentes à Bacia Sedimentar Sergipe-Alagoas. Revista Gestão Industrial, 01: 217-238.

Sacco, T; Suslick, S. B; Vidal, A. C. 2007. Modelagem Geológica 3D do Campo de Namorado Utilizando Dados de Perfilagem de Poços Verticais. $4^{\circ}$ Congresso Brasileiro de Pesquisa e Desenvolvimento em Petróleo e Gás, Campinas.

Silva, C. A. M; Rocha, P. L. F; Oliveira, J. K. 2009. Estimativa de litofácies através de perfis de poços do Campo de Namorado (Bacia de Campos, RJ). 11th International Congress of the Brazilian Geophysical Society, Salvador. 